\title{
Potential and Cell Density Dependences of Extracellular Electron Transfer of Anode-Respiring Geobacter sulfurreducens Cells
}

\section{Shoichi MATSUDA, ${ }^{a}$ Huan LIU, ${ }^{b}$ Kazuhito HASHIMOTO, ${ }^{a, b, c, *}$ and Shuji NAKANISHI ${ }^{b, c, *}$}

a Department of Applied Chemistry, School of Engineering, The University of Tokyo, 7-3-1 Hongo, Bunkyo-ku, Tokyo 113-8656, Japan

b Research Center for Advanced Science and Technology, The University of Tokyo, 4-6-1 Komaba, Meguro-ku, Tokyo 153-8904, Japan

c ERATO/JST, HASHIMOTO Light Energy Conversion Project, 7-3-1 Hongo, Bunkyo-ku, Tokyo 113-8656, Japan

* Corresponding author: nakanishi@light.t.u-tokyo.ac.jp

\section{ABSTRACT}

Geobacter sulfurreducens has been extensively studied as a model electricity-producing microbes and it is now well known that extracellular electron transfer (EET) to an anode in this microbe is mediated through the expression of abundant outer membrane c-type cytochromes (OMCs). As the electrons need to travel across the biofilm formed on an anode, the macroscopic EET activity depends on the biofilm thickness. In this sense, it is worth investigating how the EET current depends on the optical cell density (OD) in the electrochemical chamber. Here we report that the OD value strongly affects on the relationship between the EET current and the anode potential.

(c) The Electrochemical Society of Japan, All rights reserved.

Keywords : Extracellular Electron Transfer, Metal-Reducing Bacteria, Cytochrome, Microbial Fuel Cell

\section{Introduction}

Extracellular electron transfer (EET) is a key process in the energy conversion between electrical and chemical energy, particularly related to microbial fuel cells $(\mathrm{MFCs})^{1-7}$ and microbial electrolysis cells (MECs) ${ }^{8,9}$ In MFCs, respiratory electrons injected from organic electron donors are transferred to electrodes either with or without exogenous mediators; thus, MFCs provide a promising approach for harvesting electrical energy from aquatic sediments and waste organic matters. MECs are another type of microbe-based device that produce chemical fuels, such as hydrogen and methane, with the assistance of electricity-producing microbes. Geobacter sulfurreducens has been extensively studied as a model electricityproducing microbes and it is now well known that EET to an anode in this microbe is mediated through the expression of abundant outer membrane $c$-type cytochromes (OMCs) $)^{10-14}$ (Fig. 1a).

The EET ability to an anode can be sophisticatedly investigated by three-electrode electrochemical system equipped with a reference electrode, which allows the precise tuning of the anode potential and the direct detection of the EET activity as an electric current. Due to the advantages, the electrochemical technique has proven to be very powerful for studying respiratory EET in bacteria. We have previously revealed that EET current of G. sulfurreducens cells strongly depended on the anode potential when the optical cell density (OD) in the media was high. ${ }^{15}$ In such a high OD system, thick biofilms were formed on the anode. Therefore, each cell in the biofilm is put on an inhomogeneous micro-environment, which might affect on the macroscopic EET current from the population of the cells (i.e., the biofilms). In this sense, it is worth investigating whether the EET current depends on the OD value or not. In the present work, we examined the OD dependence of the EET current and revealed that the OD value strongly affects on the relationship between the EET current and the anode potential.

\section{Experimental}

\subsection{Microbe preparation}

G. sulfurreducens PCA was cultured anaerobically at $30^{\circ} \mathrm{C}$ for

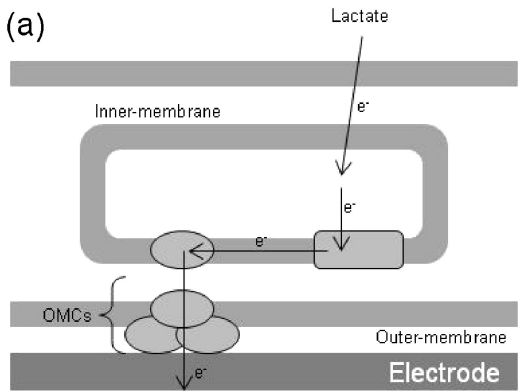

(b) Reference electrode ( $\mathrm{Ag} \mid \mathrm{AgCl})$

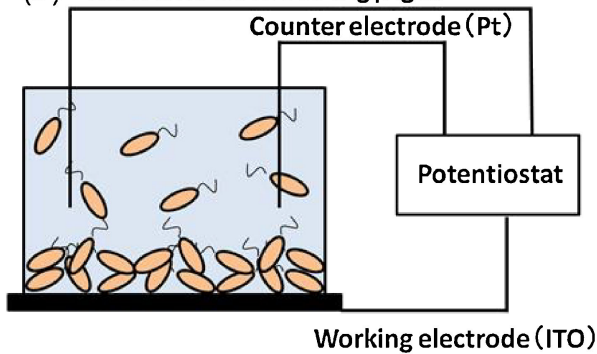

Figure 1. (Color online) Schematic illustrations of (a) the extracellular electron transfer from the bacterial cells to an anode and of (b) experimental setup.

$72 \mathrm{~h}$ in $50 \mathrm{~mL}$ PS medium $\left(\mathrm{NaHCO}_{3}(0.42 \mathrm{~g}), \mathrm{CaCl}_{2} \cdot 2 \mathrm{H}_{2} \mathrm{O}(0.07 \mathrm{~g})\right.$, $\mathrm{NH}_{4} \mathrm{Cl}(0.54 \mathrm{~g}), \mathrm{MgCl}_{2} \cdot 6 \mathrm{H}_{2} \mathrm{O}(0.1 \mathrm{~g}), \mathrm{KH}_{2} \mathrm{PO}_{4}(0.14 \mathrm{~g})$, HEPES $(2.38 \mathrm{~g})$, yeast extract $(0.5 \mathrm{~g}), 1 \mathrm{~mL}$ trace element solution $\left(\mathrm{FeCl}_{2}\right.$ $(10 \mathrm{mM}), \mathrm{CoCl}_{2}(1 \mathrm{mM}), \mathrm{MnCl}_{2} \cdot 4 \mathrm{H}_{2} \mathrm{O}(1 \mathrm{mM}), \mathrm{ZnCl}_{2}(1 \mathrm{mM})$, $\mathrm{H}_{3} \mathrm{BO}_{3}(0.1 \mathrm{mM}), \mathrm{NiCl}_{2}(0.1 \mathrm{mM}), \mathrm{AlCl}_{3}(0.1 \mathrm{mM}), \mathrm{Na}_{2} \mathrm{MoO}_{4} \cdot 2 \mathrm{H}_{2} \mathrm{O}$ $\left.(0.1 \mathrm{mM}), \mathrm{CuCl}_{2}(0.01 \mathrm{mM})\right)$, and $1 \mathrm{~mL} \mathrm{Se} / \mathrm{W}$ solution $\left(\mathrm{Na}_{2} \mathrm{SeO}_{3}\right.$ $\left.(0.01 \mathrm{mM}), \mathrm{Na}_{2} \mathrm{WO}_{4} \cdot \mathrm{H}_{2} \mathrm{O}(0.01 \mathrm{mM})\right)$, per liter) supplemented with acetate $(10 \mathrm{mM})$ as a carbon source and fumarate $(40 \mathrm{mM})$ as an electron acceptor. Cells were then collected and washed three times with PS medium by centrifugation for $5 \mathrm{~min}$ at $5,000 \times \mathrm{g}$. After the final wash, the cell suspension was centrifuged for $20 \mathrm{~min}$ at 


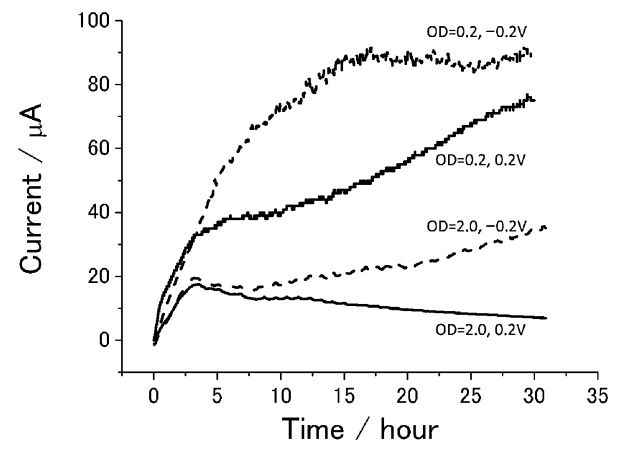

Figure 2. Time course of microbial current in a high OD $(=2.0)$ system and a low OD $(=0.2)$ system at either $+0.2 \mathrm{~V}$ (solid curve) and $-0.2 \mathrm{~V}$ (dashed curve).

$5,000 \times \mathrm{g}$, and the collected cells were used for electrochemical characterization. Cells were injected into the electrochemical cell (described below) using a 1-mL syringe (Terumo) equipped with a 21 gauge needle. The concentration of the cell suspension in the electrochemical cell was determined by measuring the optical density at $600 \mathrm{~nm}(\mathrm{OD})$ and adjusted to $\mathrm{OD}=2.0$ or 0.2 .

\subsection{Electrochemical characterization}

A single-chamber, three-electrode system was used to monitor the electrochemical behaviour of $G$. sulfurreducens. A tin-doped $\mathrm{In}_{2} \mathrm{O}_{3}$ (ITO) glass with a surface area of $3.2 \mathrm{~cm}^{2}$ was used as the working electrode and was mounted on the bottom of the reactor (Fig. 1b). Microbes injected into the reactor gradually settled on the electrode surface with time. After long-time electrochemical cultivation, pink-color biofilms are formed on the anode. The color of the biofilm was more reddish when higher OD suspension was used, suggesting that thicker biofilms were formed in the high OD system. We confirmed that the ITO electrode was stable in the potential and $\mathrm{pH}$ ranges that were used in this study. The electrical conductivity of ITO did not change, even after the completion of the electrochemical cell experiments. $\mathrm{An} \mathrm{Ag} / \mathrm{AgCl}$ (sat. $\mathrm{KCl}$ ) and a platinum wire were used as the reference and counter electrodes, respectively. $4 \mathrm{~mL}$ PS medium containing acetate $(50 \mathrm{mM})$ was used as the electrolyte. The electrolyte was deaerated by $\mathrm{N}_{2}$ bubbling for $30 \mathrm{~min}$ before measurements. The temperature of the electrochemical cell was maintained at $30^{\circ} \mathrm{C}$.

\section{Results and Discussion}

The curves shown in Fig. 2 are time courses of the EET currents generated by $G$. sulfurreducens cells at $-0.2 \mathrm{~V}$ and $0.2 \mathrm{~V}$. The EET current increased with time at all the potentials during the experiment (within 35 hours). The decrease in the EET current due to the depletion of acetate, the electron donor, can be observed about 60 hours after the electrochemical cultivation has started. In fact, the addition of acetate, the electron donor, did not cause the increase in the increase in the EET at 35 hours, indicating that acetate (the electron donor) was not depleted during the experiments in Fig. 2. The EET currents after $35 \mathrm{~h}$ of electrochemical culture in a suspension containing a high density of cells (OD of 2.0), where the current values were stabilized, are plotted against the anode potential (squares in Fig. 3). The EET current first appeared at approx. $-0.4 \mathrm{~V}$, reached a maximum value at approx. $-0.15 \mathrm{~V}$ (the region-I), and then decreased in the potential region more positive than $-0.15 \mathrm{~V}$ (the region-II). As reported previously, ${ }^{15}$ we did not detect obvious differences in the biofilm thickness or cell density on the anode surface by in-situ and ex-situ optical scanning electron microscopic inspection, and the EET current responded to an alternate change of the potential in a reversible manner in spite of

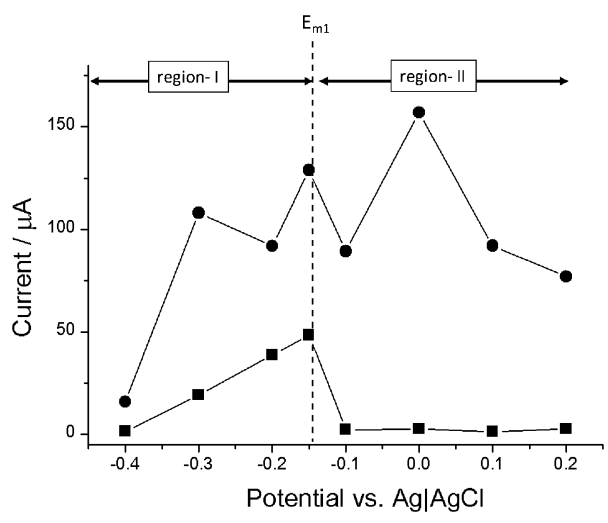

Figure 3. Microbial current $35 \mathrm{~h}$ after the electrode potentials were poised at the indicated potentials in a high OD $(=2.0)$ system (squares) and a low OD $(=0.2)$ system (circles). $E_{\mathrm{m} 1}$, denotes the mid-point potentials of redox peaks 1 extracted from the previous work. ${ }^{15}$

the fact that the biofilm thickness and cell density on the anode did not change during this measurement. Furthermore, we confirmed cell density and $\mathrm{pH}$ value of the media were stable during the electrochemical cultivation at all the potentials. These results indicate that the reduced current in the region-II is not due to the reduction in the number of cells participating in the current generation and to the difference in the media environment surrounding the cells, but rather to the metabolic activity of cells. Contrary to this results, in case the experiments were performed in a suspension containing a low density of cells $(\mathrm{OD}=0.2)$, the EET current did not exhibit clear anode potential dependence (circles in Fig. 3). Notably, the EET currents in a suspension with low OD were higher than those in a suspension with high OD. This can be because of that the diffusion of acetate (electron donor) to the electrochemical interface is more effective in the low OD system as the concentration of cells on the electrode surface is much smaller in the low OD system compared with the high OD system.

The biofilms formed on the anode were also subjected to cyclic voltammetry measurements. Figure 4a shows two cyclic voltammograms $(\mathrm{CV})$ for the biofilms formed at $+0.2 \mathrm{~V}$ (solid curve) and $-0.2 \mathrm{~V}$ (dashed curve) in the higher OD system. We have previously reported that three different couple of redox peaks (peaks 1, 2, and 3) can be observed in the CV. ${ }^{15}$ The relative intensity of the peaks strongly depends on the poised potential, ${ }^{15}$ and only the redox peaks 1 can be clearly seen in the present case. The CVs contain information both of steady-state biocatalytic current and redox reaction current at the cells/electrode interface. When the steadystate biocatalytic current is small $(\mathrm{OD}=2.0,+0.2 \mathrm{~V})$, only the redox peaks originating from the redox reactions at the cells/ electrode interface are well highlighted (solid curve, Fig. 4a). On the other hand, for the other culture conditions where relatively larger biocatalytic current flows, both of the biocatalytic current and the redox peaks are overlapped in the CVs (for example, dashed curve in Fig. 4a).

In the CVs, the cathodic peak is always larger than the anodic one. A possible explanation for this fact is as follows. Acetate, the electron donor for the respiration, cannot be transported effectively to the cells adsorbed on the electrode (1st layer cells) due to the presence of over 2nd layer cells. On the other hand, electron injection from the electrode to the cells is possible only for the $1 \mathrm{st}$ layer cells. The imbalanceness can cause the asymmetric feature of the redox peaks. In fact, the redox peaks becomes more symmetric when the potential scan rate is set to be very fast (such as $50 \mathrm{~V} \mathrm{~s}^{-1}$ ) as reported previously. ${ }^{16}$ 

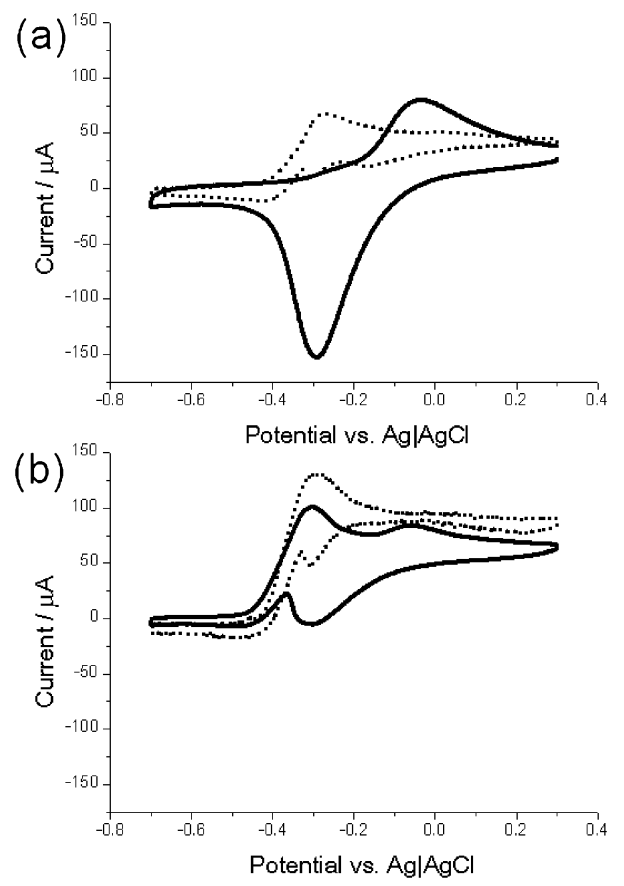

Figure 4. Whole-cell cyclic voltammograms of biofilms formed in (a) a high OD (=2.0) system and in (b) low OD (=0.2) system, cultured at either $+0.2 \mathrm{~V}$ (solid curve) and $-0.2 \mathrm{~V}$ (dashed curve). The scan rate of the potential was $50 \mathrm{mV} \mathrm{s}^{-1}$.

There are various arguments about the biochemical origin of the redox peaks in the CVs. Some of the outer membrane cytochromes in the Geobacter cells have been purified, and the redox potential of the purified proteins were clarified. ${ }^{17-19}$ However, it has not been revealed about the relationship between the redox peaks in the $\mathrm{CV}$ and the proteins. In the system, not only cell surface redox protein but some diffusive redox chemicals such as flavins, quinons, and secreted cytochromes can contribute to the appearance of the redox peaks. As the onset potential of the biocatalytic current is about $250 \mathrm{mV}$ more negative than the midpoint potential of the redox species 1 , it is unlikely that the redox species 1 mediates the biocatalytic current. It should be noted here that the intensity of the peak 1 varied depending on the poised potential, i.e., the peak 1 was much larger when the biofilm was grown at $+0.2 \mathrm{~V}$ (solid curve) than at $-0.2 \mathrm{~V}$ (dashed curve). On the other hand, when the biofilms were grown in a cell suspension with lower OD $(=0.2)$, the potential dependence of the intensity of the peak 1 was almost lost as shown in Fig. $4 b$.

For the solid curve in Fig. 4a, the biocatalytic current seems not to flow from $-0.4 \mathrm{~V}$, contrary to the other cases in Fig. 4. This is because of that the biocatalytic current becomes very low when the cells are cultured at $+0.2 \mathrm{~V}$ with $\mathrm{OD}=2.0$ condition. In case the cells were initially cultured at $-0.2 \mathrm{~V}$, the intensity of the peak 1 is small and relatively larger biocatalytic current flows as shown in Fig. 4a (dashed curve). When the poised potential is suddenly changed from -0.2 to $+0.2 \mathrm{~V}$, the larger current keeps flowing and the redox peak 1 grows as shown in Fig. 5. In this case, it can be clearly seen that the biocatalytic current starts to flow at $-0.4 \mathrm{~V}$.

To clarify how the intensity of the peak 1 in the $\mathrm{CV}$ varies with electrode potential, the biofilms formed at several potentials are subjected to the $\mathrm{CV}$ and the anodic peak area of the peak $1\left(Q_{1}\right)$ are plotted against the poised potential as shown in Fig. $6 .{ }^{20}$ From this analysis, it was revealed that the behavior of the CV drastically changed at around the $E_{\mathrm{m} 1}$ in the high OD system (squares in Fig. 6). Contrary to the case with the high OD system, the potential dependence of the $Q_{1}$ value was lost in the low OD system (circles

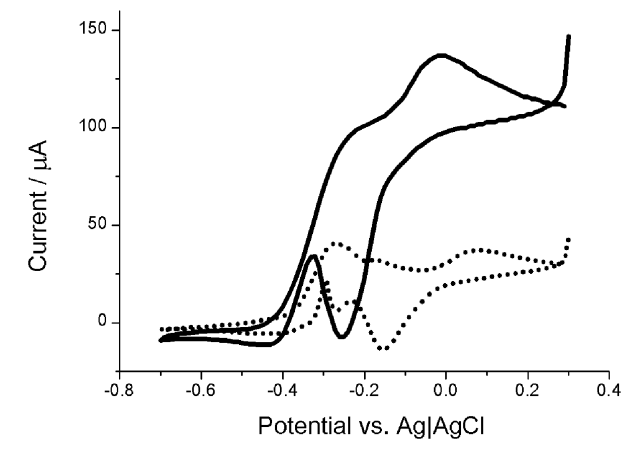

Figure 5. Whole-cell cyclic voltammograms of biofilms formed in a high OD $(=2.0)$ system cultured at $-0.2 \mathrm{~V}$ (dashed curve) and switched to $0.2 \mathrm{~V}$ (solid curve). The scan rate of the potential was $50 \mathrm{mV} \mathrm{s}^{-1}$.

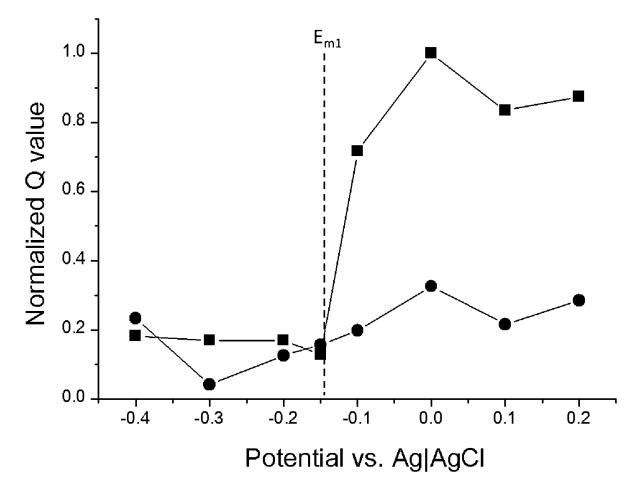

Figure 6. Normalized anodic peak areas $\left(Q_{1}\right)$ plotted against the potential in a high OD $(=2.0)$ system (squares) and a low OD (=0.2) system (circles). The normalization was performed using the $Q_{1}$ value at $+0.2 \mathrm{~V}$ in high $\mathrm{OD}$ system. $E_{\mathrm{m} 1}$, denotes the mid-point potentials of redox peaks 1 extracted from the previous work. ${ }^{15}$

in Fig. 6). Thus, the OD affected not only on the potential dependence of the EET (Fig. 3) but on the intensity of the peak 1 (Fig. 6). Importantly, both the EET current and the $Q_{1}$ value drastically changed at $E_{\mathrm{m} 1}$. More concretely, the EET current becomes lower in the potential region more positive than the $E_{\mathrm{m} 1}$ (i.e., the region-II). However, in the lower OD system, the $Q_{1}$ value was much smaller and the EET current was kept high even in the region-II.

Let us summarize our experimental results (Table 1). When the $Q$ value is larger (the region-II in the high OD system), the EET current is lower. On the other hand, when the $Q$ value is smaller (the regionI in the high OD system and the regions I and II in the lower OD system), the EET current is higher. This result indicates that the redox state of the redox species 1 affects on the EET activity, although it is unlikely that the redox species 1 is the protein directly medating the biocatalytic current. We speculated that the intracellular redox environment becomes more oxidative when the $Q$ value is larger. In general, activities of various enzymes and expression levels of the genes related to the electron transfer become lower when the intracellular redox environment becomes too oxidative. $^{21,22}$ The redox-responsivities are thought to be an appearance of the self-protection ability of living cells. Although we are presently unclear as to potential dependence of the EET of anode-respiring $G$. sulfurreducens cells, studies for clarifying the biomolecular mechanism are currently in progress in our laboratory. Our findings reported in the present paper might be one of such ability inherent in G. sulfurreducens cells. We anticipate that our findings will contribute to the development of energy conversion systems where bacterial biofilms play a critical role. 
Table 1. (Color online) Summary of the qualitative relationship among the OD value, the EET activity, the $Q_{1}$ value, and the anode potential.

\begin{tabular}{|c|c|c|c|}
\hline & Region-I & Region-II \\
\hline $\begin{array}{c}\text { High OD } \\
(=2.0)\end{array}$ & EET activity & High & Low \\
\hline $\begin{array}{c}\text { Low OD } \\
(=0.2)\end{array}$ & EET activity & High & High \\
\hline & Q value & Small & Small \\
\hline
\end{tabular}

\section{Acknowledgment}

This work was financially supported by the Exploratory Research for Advanced Technology (ERATO) program of the Japan Science and Technology Agency (JST).

\section{References}

1. D. R. Lovley, Nat. Rev. Microbiol., 4, 497 (2006).

2. K. Rabaey and W. Verstraete, Trends Microbiol., 23, 291 (2005).

3. B. E. Logan, Nat. Rev. Microbiol., 7, 375 (2009).
4. A. E. Franks and K. P. Nevin, Energies, 3, 899 (2010).

5. B. E. Logan, B. Hamelers, R. A. Rozendai, U. Schrorder, J. Keller, S. Freguia, P. Aelterman, W. Verstraete, and K. Rabaey, Environ. Sci. Technol., 40, 5181 (2006).

6. L. Shi, D. J. Richardson, Z. Wang, S. N. Kerisit, K. M. Rosso, J. M. Zachara, and J. K. Fredrickson, Environ. Microbiol. Rep., 1, 220 (2009).

7. D. R. Bond, D. E. Holmes, L. M. Tender, and D. R. Lovley, Science, 295, 483 (2002).

8. B. E. Logan, D. Call, S. Cheng, H. V. M. Hamelers, T. H. J. A. Sleutels, A. W. Jeermiasse, and R. A. Rozendai, Environ. Sci. Technol., 42, 8630 (2008).

9. H. V. M. Mamelers, A. TerHeijne, T. H. J. A. Sleutels, A. W. Jereminasse, D. P. B. T. B. Strik, and C. J. N. Buisman, Appl. Microbiol. Biotechnol., 85, 1673 (2010).

10. D. E. Holmes, T. Mester, R. A. O'Neil, L. A. Perpetua, M. J. Larrahondo, R. Glaven, M. L. Sharma, J. E. Ward, K. P. Nevin, and D. R. Lovley, Microbiology, 154, 1422 (2008).

11. C. Leang, M. V. Coppi, and D. R. Lovley, J. Bacteriol., 185, 2096 (2003).

12. T. Mehta, S. E. Childers, R. Glaven, D. R. Lovley, and T. Mester, Microbiology, 152, 2257 (2006).

13. T. Mehta, M. V. Coppi, S. E. Childers, and D. R. Lovley, Appl. Environ. Microbiol., 71, 8634 (2005).

14. K. P. Nevin, B. C. Kim, R. H. Glaven, J. P. Johnson, T. L. Woodard, B. A. Methe, R. J. Didonato, S. F. Covalla, A. E. Franks, A. Liu, and D. R. Lovley, PLoS One, 4, e5628 (2009).

15. S. Matsuda, H. Liu, S. Kato, K. Hashimoto, and S. Nakanishi, Environ. Sci. Technol., 45, 10163 (2011).

16. H. Liu, S. Matsuda, T. Kawai, K. Hashimoto, and S. Nakanishi, Chem. Commun., 47, 3870 (2011).

17. X. Qian, T. Mester, L. Morgado, T. Arakawa, M. L. Sharma, K. Inoue, C. Joseph, C. A. Salgueiro, M. J. Maroney, and D. R. Lovley, Biochim. Biophys. Acta, 1807, 404 (2011).

18. K. Inoue, X. Qian, L. Morgado, B. Kim, T. Mester, M. Izallalen, C. A. Salgueiro, and D. R. Lovley, Appl. Environ. Microbiol., 76, 3999 (2010).

19. T. S. Magnuson, N. Isoyama, A. L. Hodges-Myerson, G. Davidson, M. J. Maroney, G. G. Geesey, and D. R. Lovley, Biochem. J., 359, 147 (2001).

20. The square value of the difference of the anodic peak current and the background biocatalytic current was set to be the $Q$ value.

21. C. Bauer, S. Elsen, and T. H. Bird, Annu. Rev. Microbiol., 53, 495 (1999).

22. J. Green and M. S. Paget, Nat. Microbiol., 2, 954 (2004). 